\title{
Grandes Discusiones del Feminismo. Democracia y Retos para la ciudadanía ecuatoriana
}

\section{Large Discussions about Feminism. Democracy and Challenges for Ecuadorian citizenship}

Shakira Nicole Galarza Quinchiguango

Recepción: 18 de junio de 2018

Aceptación: 02 de octubre de 2018

\begin{abstract}
Resumen
El presente artículo explora la ampliación a la conceptualización del feminismo y la inserción de las teorías de género, a través de breves recorridos por hitos históricos, que dieron paso a la aparición de más elementos a consideración. Asimismo, a lo largo de sus tres apartados, se revisa la lógica propuesta por Fraser del reconocimiento y distribución con el fin de entenderla ligada a conceptualizaciones como la democracia y la ciudadanía. Finalmente, este escrito analiza la noción de la equidad de género en el escenario ecuatoriano, y a través de dos ejemplos, se evidencia la idea conservadora predominante en el país, en contraposición a la idea de adaptar y promocionar el género inscrito en instrumentos internacionales.

Palabras clave: feminismo, género, reconocimiento- distribución, democracia, ciudadanía.

\section{Abstract}

The following article explores the enlargement of the feminist conceptualization and the introduction of the genre theories through a historical revision of facts that brought about new elements to be taken into consideration in the discussion. Likewise, along the three sections Fraser's logic proposal of distribution and recognition is reviewed to understand it joint with concepts as democracy and citizenship. Finally, this paper analyses the genre equality notion in Ecuador's scenery, and taking two examples the predominant conservative ideology is evidenced, against the idea of adopt and promote the genre theories contended on international legislations.

Key words: feminism, genre, recognition-distribution, democracy, citizenship.
\end{abstract}




\section{Introducción}

El presente artículo propone realizar una revisión de las nociones de género y feminismo, para entender la dinámica en su concepción, incidida por taxonomías que han sido fruto de la sociedad actual, de acontecimientos históricos y de particularidades que responden a grupos poblacionales. De igual forma, se propone referenciar momentos históricos que han sido influyentes para el movimiento y que han acabado por ampliar sus luchas y consolidar algunos de sus fines. Así, para lograr este objetivo, se revisan algunos de los) principales preceptos teóricos promovidos por importantes autoras como Nancy Fraser (2015) y Judith Butler (1990; 1992; 2002), los cuales brindan lineamientos conceptuales que serán revisados en este ensayo. La primera autora, permite la compresión de su propuesta alrededor de la lógica o dualidad de reconocimiento/distribución. Esta indica un tipo de estructura de la sociedad y de desarrollo de una igualdad social, solamente cuando los sujetos alcanzan el mismo nivel de visibilidad, de adquisición y de goce de derechos. La dualidad de reconocimiento/distribución transversalizará los diferentes apartados de este ensayo, afirmándose y leyéndose conjuntamente como las discusiones propuestas. Mientras que, la segunda autora, incidirá en este ensayo respecto a su aporte relacionado a la ampliación del sujeto del feminismo y con este la visibilidad de las teorías de género a través de la entidad sexo-genéricas. En adición, esta autora será retomada en el último apartado en relación a conceptualizaciones que podría frenar el desarrollo social.

Este escrito está distribuido en tres apartados que presentan los siguientes objetivos. El primer apartado efectúa una revisión de los fines y ampliaciones conceptuales que surgen alrededor de los movimientos de género $\mathrm{y}$ feminismo, examinando su causa $\mathrm{y}$, de manera breve, contextualizando para entender el porqué de su inmersión; así como, se hace alusión a posibles riesgos en tal ampliación que pueden mermar las luchas que promueven estos movimientos. El segundo apartado, revisa la importancia de la consideración del género y del feminismo en los regímenes democráticos y en la conceptualización de ciudadanía, así a la par que se indican sus implicaciones, se relaciona y entiende la acción de la lógica reconocimientodistribución. Finalmente, el último apartado refiere a los avances históricos 
de las luchas género-feministas y problematiza los avances reales en cuanto al desarrollo de una democracia y de una ciudadanía inclusiva en el Ecuador, a través de dos ejemplos que indicarán que el país tiene aún larga trayectoria por recorrer en esta materia.

\section{Acepciones teóricas y entendimientos}

Más allá de las nociones conferidas por los diccionarios o por los Glosarios de Género, el feminismo engloba una historia de lucha por la persecución de objetivos, de conquistas a través del tiempo, de reacciones y de ampliaciones. De manera que, se vuelve una conceptualización con una gran variedad de adjetivos que engloban las taxonomías o categorías como género, clase, raza, representatividad, entre otras. Así, la definición del término como "Doctrina y movimiento social que pide para la mujer el reconocimiento de unas capacidades y unos derechos que tradicionalmente han estado reservados para los hombres" (-DRAL, 2017), se ha quedado en una etapa prematura y no se presta para explicar la ajetreada realidad social de nuestros días. Actualmente, cuando se habla de feminismo, además de remitir a las denominadas tres olas, se habla de aspectos que evocan temas inter-transversalizados que se encuentran en lo social, en lo económico o en lo político.

Consecuentemente, no hace falta referirse al término simplemente de forma histórica- descriptiva, como se realiza para hablar de los logros del movimiento que van desde la época de la Ilustración o con el movimiento de mujeres sufragistas, en la primera ola. El mismo que se conecta con la segunda en el refuerzo y en mejoras en los derechos sociales y laborales (especialmente en la época de los 60 y con grandes exponentes como De Beauvoir). Por último, hasta llegar a la tercera con discusiones contemporáneas en busca de la equidad e identificando variaciones y matices (Hera, 2009: 77-79); no obstante, a quienes hablan de una cuarta ola en los albores del último siglo.

Las más recientes discusiones del feminismo incluyen categorías conceptuales, a veces binarias, como las propuestas por Fraser (2003): "reconocimiento/distribución", cuyo ímpetu se encuentra en determinar cómo se crean desigualdades en la sociedad, suponiendo que estos dos 
conceptos guardan una relación proporcional directa. Así, se parte de la premisa de que la sociedad está organizada de forma en que unos pocos adquieren el reconocimiento mediante el cumplimiento de características, normas (pre)establecidas o consensos sociales tácitos, y con éste son acreedores a la distribución de derechos, privilegios o condiciones que otros, por falta del mismo no pueden gozar (p. 205). Por ejemplo, supondría que, si no existe un pleno reconocimiento de la mujer, existirán problemas en la distribución de determinados derechos, oportunidades o condiciones (laborales, educacionales, entre otros); y que, a su vez, existe un problema en la estructuración de la sociedad. De manera que unos tienen más y otros menos, mermando la concepción de justicia y de igualdad. Además, tanto el reconocimiento y la distribución de subjetividades y con estas de derechos y particularidad, impactan en aspectos como la división de trabajo, sueldos y salarios, tipo de ciudadanía, participación política, discriminación, entre otros.

Asimismo, dentro de las nuevas preocupaciones del feminismo se encuentran aspectos que lo transversalizan como, por ejemplo, la inserción del género, el cual concibe a las diferentes identidades sexuales; las mismas que se enmarcan dentro de la misma lógica de reconocimiento y distribución; solamente que a ésta se suman concepciones como el cumplimiento de la norma o la heteronormatividad.

Lo hetero-normativo, comprende la preponderancia de las prácticas heterosexuales como "normalizadas" y por tanto únicamente legítimas, y éstas estructuran aspectos políticos, sociales, o económicos (Butler, 2002). Así el individuo pasa por un proceso de asignación natural del sexo y luego por la asignación social del género, debiendo corresponder y asumir su rol hombre igual a masculinidad y mujer igual a feminidad. Por lo tanto, sugiere que quienes no cumplan con esta 'normativa', conforman un tipo de otredad (lo abyecto indicado por Butler 2002), en la cual están sometidos a un proceso de discriminación o segregación mediante el desconocimiento de sus particularidades, dando como resultado relaciones conflictivas entre grupos dentro de la misma sociedad. En cuanto a la dualidad reconocimiento/ distribución respecto al género, supone de inmediato un problema de reconocimiento de su subjetividad, en el sentido que hay una implícita 
imposición de la heterosexualidad como elemento necesario para ser un sujeto pleno, y de no ser este el caso, por ende, el goce de condiciones, derechos y estatus para desarrollarse se encuentran en riesgo o en menoscabo. Esta inserción del concepto de género en un momento histórico, fue la mayor crítica y el aporte a las teorías feministas.

Judith Butler (1990) cuestiona a la mujer como sujeto del feminismo, argumentando la existencia de otras construcciones o identidades que comparten una misma lucha, y que se intersectan con las consternaciones que conforman la lucha del feminismo (pp. 45-49). Así, se puede pensar que no solo hay atropello en la mujer en una sociedad con construcción patriarcal, sino que el problema radica en la forma en la cual está estructurada la misma, al provocar una supremacía y violencia de unos hacía otros. De esta manera, también se pueden entender las dinámicas del ejercicio de poder, en donde, por un lado, hay actos de imposición y "cuerpos que importan" (es decir quienes no están en la otredad) mientras que, por otro lado, existen aquellos que, al parecer, no cumplen con lo requerido y que son sujetos de una dominación estructural y de su propia dominación (Butler, 2002: 53-60).

Como resultado, las identidades de género tampoco cumplirían con la normatividad ni con la estructuración patriarcal de la sociedad, exponiéndose también a la vulnerabilidad. Esta concepción permite traer a discusión al escenario político/social, nuevas formulaciones teóricas como, por ejemplo, el desarrollo de nuevas masculinidades y feminidades, que permitan explicar la puesta en escena del individuo y el rompimiento de lo normativo.

Adicionalmente, el tipo de identidad y de orientación sexual transversalizan a la mujer, esto quiere decir que además de estar expuesta ante el machismo, puede estarlo aún más ante la discriminación respecto a su identidad sexo-genérica (sexo/género), pues típicamente no cumple con la heteronormatividad; y como resultado el sujeto del feminismo no puede entenderse sin remitirse al género.

Finalmente, además de la identificación sexo-genérica, se debe añadir a la discusión del feminismo las nociones de etnia, raza y clase, que constituirían junto con la anterior en los llamados 'privilegios'. Los privilegios 
comprenden una serie de características o atributos del individuo, que ya sean por su posición geográfica, su línea fenotípica, su capacidad adquisitiva y su estatus, influyen en el goce o disfrute de ciertas garantías o reconocimientos que permiten entender imposiciones o el desenvolvimiento de la persona en lo sexual, lo moral, lo político, lo económico, lo intelectual y hasta en lo estético (Devitt, 2004). La misma lógica de Fraser permite comprender la actuación de estos privilegios, ya que parten desde el postulado de la forma en la cual está construida la sociedad, la misma que durante años ha impuesto a los sujetos o los ha construido mediante un discurso de lo correcto, lo ventajoso o lo incorrecto, lo insano y lo privilegiado.

Así, por ejemplo, dentro de las críticas del feminismo a las estructuras, se habla de una construcción social patriarcal, falocéntrica (en relación a las discusiones del psicoanálisis), paternalista, machista, heteronormativa, sexista, capitalista, eurocentrista, entre otras; que suponen la dominación de un discurso en una sociedad con predominancia de un hombre, heterosexual, blanco, en medio de un sistema de producción que acumula riquezas en pocos (Amigot y Pujal, 2009). Adicionalmente, esta discusión se vincula a aquellas que sugieren que, las naciones latinoamericanas aún mantienen dentro de sus imaginarios colectivos, la presencia de la herencia colonial de estratificaciones sociales, de racismo y de un proceso de blanqueamiento. Por esto pese a la promoción de democracia pluralista y del multiculturalismo, que den paso al reconocimiento, en el proceso de distribución resultan en convertirse en estructuras ineficaces en donde la visibilidad de la otredad es realizada por el mestizaje hegemónico (Segato, 2007). Es decir, el reconocimiento/ distribución se da por unos a los otros y no de manera evolutiva social, iterando la misma estructura desigual y privilegiando a unos.

Empero, estos privilegios crearán también desigualdades entre las propias mujeres, pues se entiende que cada una de ellas tiene una realidad diferente y se desenvuelve en escenarios diferentes, presentando sus propias características que originarán algún tipo de reconocimiento en mayor o menor grado; y a su vez algún tipo de desigualdad.

Esto dará paso a varias visiones y perspectivas dentro del feminismo como, por ejemplo: feminismo de las afrodescendientes; ecofeminismo 
(ecologismo); feminismo social; pachamamismo o comunitario. Estos últimos, los desarrolla Sofía Vega (2014), en "Sumak Kawsay: Feminismos y post-crecimiento. Articulaciones para imaginar nuevas utopías", quien identifica las perspectivas feministas y discusiones, en las sociedades latinoamericanas, correspondientes a la ola de izquierda del año 2000 en adelante. Así, realiza una revisión de las principales consideraciones y perspectivas de estos feminismos, visibilizando sus diferencias de género y particularidades; que persiguen objetivos y necesidades propias, que de igual forma se ligarán con la dualidad propuesta por Fraser (2003), y les permitirá hacer uso del escenario político y de la lucha política.

Finalmente, es preciso que se mencione que las diversas perspectivas para aproximarse al feminismo y a las teorías de género no solo forman parte de las grandes discusiones, sino que también se han prestado para varias interpretaciones, que hoy en día, son asociadas con connotaciones peyorativas; muchas veces éstas han devenido con la práctica o la forma de concretizar la teoría. Así, por ejemplo, se puede discutir la relevancia o la validez de la sobreexposición del cuerpo, o sobre la evocación de vocablos que no puedan ser catalogados como misóginos o discriminatorios que trae a discusión la expresión en la vanguardia, lo "políticamente correcto". Sin embargo, la verdadera problemática alrededor de estás interpretaciones se presenta cuando más allá de responder a cosmovisiones y ocasiones, responden a procesos de promulgación de violencia. Se puede referir, por ejemplo, a los usos coloquiales y creaciones conceptuales como "Femi-nazi" "marimachas", o en su defecto, a asociaciones que no siempre son adecuadas como "grupo de lesbianas" o terminologías que podrían corresponder o acercase más al hembrismo y que atentan contra los fines del feminismo. De igual forma, en otras ocasiones la defensa de la diversidad sexo-genérica es asociada con un intento de volcar al sistema e instaurar uno inmoral que, al parecer, solo busca la abolición de la "familia común" (una familia constituida por padre, madre e hijos) (Vega, 2014).

Por último, lo anterior denota una serie de confusiones que hacen que los objetivos que persiguen las teorías de género y propuestas del feminismo se debiliten. Por esta razón, es una gran responsabilidad el análisis de los preceptos principales o los pilares de la búsqueda de la igualdad de género 
y trazar lineamientos; de manera que sigan respondiendo no solo a las demandas de mujeres y grupos LGTBI (minoritarios), sino que sirvan a la sociedad para la materia que tratan y los fines que persiguen con el propósito de crear sociedades más informadas, democráticas, tolerantes y pluralistas.

\section{Discusiones de Género-feminismo y ciudadanía - democracia:}

Las discusiones de género y feminismo han sido fuente de inspiración para que se discuta arduamente su relevancia en materia y en nociones de regímenes políticos, como un factor que debe ser tomando en cuenta para determinar o tratar calidades en los mismos. La democracia como régimen, para que sea entendida y designada como tal, debe cumplir con la existencia de ciertas condiciones de carácter procedimental (condiciones mínimas) y de carácter sustancial (condiciones ampliadas) en discusiones más actuales para su prospero desarrollo (en términos de Robert Dahl [1989] se hablaría de poliarquía) (Quiroga, 2000: 360-369). Así, de acuerdo a los avances y al mantenimiento de estos indicadores, la democracia se cuida de no caer en sus contrarios y de garantizar libertades (para la definición liberal) o el bien común (para la definición republicana de Mouffe; 1992). No obstante, al suponer este régimen la supremacía de la voluntad del pueblo y el cumplimiento de algunos indicadores que forman parte de su definición mínima, las discusiones relacionadas al feminismo y al género aparecen desde el entendimiento y ligazón con la relevancia de la noción de ciudadanía; la cual supone el ejercicio de unos deberes y el goce de derechos (Molyneux, 2000: 3). Esta conceptualización, tal como se anticipó anteriormente, se ve estrechamente incidida por las nociones de género, sexo, clase y raza que suponen una mayor o menor adquisición dentro de la lógica del reconocimiento y la distribución. De esta manera se puede hablar de una adecuada funcionalidad de la democracia si se sabe que el ejercicio de la ciudadanía ha alcanzado una serie de preceptos; donde el/la ciudadano/a es quien fortalece y participa para el funcionamiento de la misma. Además, el ejercicio de una ciudadanía adecuada fortalece los valores democráticos, generando idealmente un ambiente de confianza, justicia, convivencia y respeto a la pluralidad y diversidad (Kymlicka y Norman, 1994). 
Asimismo, la conceptualización de ciudadanía está inmersa dentro de la discusión de la democracia siendo relevante enfatizar al género y al feminismo dentro de esta conceptualización. Así, siguiendo a Kymlicka y Norman (1994) la ciudadanía posee dos vertientes, en donde, por un lado, comprende los aspectos legales y, por el otro, comprende el ejercicio de la misma en diversas instancias. El primero conlleva la adquisición y disposición de una serie de derechos y responsabilidades, políticas, civiles y sociales; mientras que el segundo, añade las diversidades que se presentan en la sociedad (grupos sociales y culturales) (p.83). Tanto para la una como para la otra, las discusiones sobre la igualdad de género son un aspecto relevante, pues significan un punto de inflexión en el quehacer político, económico-social, y judicial ejercidos por los principales poderes del Estado, permitiendo la creación de lineamientos y mecanismos para salvaguardar el bienestar poblacional; al tiempo que se reconocen particularidades.

Consecuentemente, el feminismo es retomado dentro de la democracia y problematizado dentro de las discusiones de ciudadanía, al ser, más allá de un movimiento ideológico, social y político, un instrumento que provee de contenido a determinados procesos democráticos (Facio y Fries, 1999: 3). Esto significa que trae consigo la inserción y el reconocimiento de determinadas condiciones (sociales, políticas, legales, etc.) que mejoren la calidad de vida para estos grupos poblacionales; así como la atribución de determinadas garantías para tal reconocimiento. Una sociedad democrática no puede descuidar aquellas causas por las que aboga el feminismo, y no se puede hablar de una ciudadanía, en sus dos vertientes, sino se atañe o amplía este concepto para las luchas que el movimiento promueve. De la misma manera, las discusiones de género apuntan a terminar con la censura cultural que determina el plano social en el que deben desempeñarse hombres y mujeres (macho/hembra), librando a la sociedad de reduccionismos biológicos, que se encargan de disimular las diferencias de orden económico social, político e ideológico (Wittig, 2006: 22 en INADI, 2016: 22) y que orientan al desarrollo de ciudadanías diferenciadas de un mayor/ menor reconocimiento y distribución de derechos y garantías. Es por esto, finalmente, que las discusiones sobre género y mujer han sido politizadas, porque suponen el alcance y la declaración de un estatus ciudadano y del goce 
de los derechos que confiere el régimen democrático a través del gobierno y del aparato jurídico; y razón por la cual los movimientos de activistas LGTBI y de mujeres claman.

Dentro de la estructura patriarcal de la sociedad, el desarrollo óptimo de la democracia y de la ciudadanía se ve obstaculizado, tanto para la mujer como para las identidades de género, así como, para el resto de la población. Esto sucede porque esta estructura mantiene la concepción de un sistema histórico construido, en el cual existen dos premisas: una supremacía del hombre y una subordinación de la mujer respecto al hombre, y dos categorías sexo-genéricas legitimadas (o impuestas) y autorizadas (Donaldson, 1993: 645; en Troya, 2001: 69). Esto permite que, mayoritariamente, el hombre se encuentre en una posición de dominación y control de las instituciones en la sociedad como son la familia, la iglesia, el Estado; y de las relaciones de poder en lo económico, lo académico- científico, lo político y lo social. (Facio y Fries, 2005: 25-29). Así, la lógica del reconocimiento y distribución se determina bajo la lente de lo masculino, del hombre, y será a partir de este, que produzca la construcción de una ciudadanía para la mujer y para el género, asignándole espacios, roles, obligaciones y derechos; es decir, una ciudadanía de la otredad respecto al hombre. Esto hace que sea lento y arduo el procedimiento para el goce de una ciudadanía plena y activa y de una democracia participativa inclusiva. Adicionalmente, y enmarcando en la lógica de reconocimiento y distribución indicada en la sección anterior, las distinciones entre individuos (o el reconocimiento de los sujetos del feminismo y del género) deberían entenderse desde la concepción de la búsqueda de la igualdad entre seres humanos, y no radicar, principalmente, en reduccionismos y/o diferenciaciones biológicas, y menos aún desde una lectura de una sociedad patriarcal.

La historia permite, por ejemplo, denotar el proceso de adquisición y ampliación de derechos civiles, sociales y políticos de las mujeres y de los grupos de LGTBI, y con estos de la ciudadanía. Así, de manera breve se puede mencionar, aquel recorrido que va desde el paso de la concepción de la subjetividad de la mujer ligada al hombre, que suponía no solo a la falta de reconocimiento de la individualidad de la mujer, sino que implicaba la pertenencia de la mujer al hombre. Por ejemplo, la instauración de 
subordinación de la mujer frente al padre y al marido; la pérdida de apellido en la sociedad conyugal y la reducción de derechos (Facio y Fries, 1999: 9- 14). Luego, la concepción como ciudadana media y los movimientos de sufragistas, sindicalistas y laboristas, donde se puede mencionar la inclusión del derecho al voto universal de la mujer en la Declaración Universal de los Derechos Humanos de 1948, o los alcances en Argentina con el movimiento de mujeres lideradas por la figura de Eva Perón, quien tuvo un fuerte protagonismo incentivando el lema de "las madres de los soldados de Perón", dando visibilidad a la mujer en lo público (Molyneux, 2000: 14). Finalmente, se puede referenciar a los movimientos políticos, en donde existen bancadas de mujeres en el poder legislativo, que promueven el feminismo y la promulgación de constituciones con enfoque en la equidad actualmente como es el caso de México (véase Cimanoticias septiembre 2016, sección Participación Mujeres en la política) y los programas de empoderamiento femenino de organizaciones como Naciones Unidas (UNWOMEN). Empero, es preciso diferenciar que el proceso de ampliación ciudadana para la mujer dista mucho entre los movimientos feministas de América Latina y los europeos, norteamericanos o canadienses. Los primeros se van a caracterizar por ser un feminismo mayoritariamente social y por, en reivindicadas ocasiones, enzarzar la figura de la mujer ligada a la maternidad y a la familia. Este es el caso del feminismo compensatorio en Uruguay y de las mujeres de Eva Perón, "Madres de los soldados de Perón" (ver Molyneux, 2000: 13).

En cambio, en cuestiones de género, la trayectoria data desde la dura condenación del homoerotismo del siglo XVII y XVIII; luego, por las discusiones entre la patologización o medicalización de la homosexualidad y la despenalización de la sodomía a mediados del siglo XIX (Conejo, 2007: 89-91). En estas discusiones, cabe hacer hincapié en la importancia del discurso cientista que, mediante variados diccionarios de psiquiatría, categorizaba la homosexualidad como una patología o una desviación, frente a la necesidad de salvaguardar el orden público, mediante la criminalización de conductas fuera de la moral aceptada. Posteriormente, y aprovechando los cambios instaurados por la revolución sexual y debido a las reiteradas persecuciones atentatorias a los derechos de homosexuales, a finales de 1969 en Estados Unidos, aparece en Greenwich Village la rebelión gay que 
dará origen a la creación y liberación de todo un movimiento que agrupa diversidades sexuales, cuya más fuerte materialización se realiza cada año en junio en el "Desfile del Orgullo Gay" (Arboleda, 2017).

En la actualidad, las discusiones giran en torno al reconocimiento de derechos reproductivos como el aborto; pensiones alimenticias justas; sueldos y salarios paritarios; cumplimiento de ley de cuotas; reconocimiento de matrimonios entre parejas del mismo sexo y adopción, que al parecer atentan contra lo demarcado por la sociedad patriarcal como la familia nuclear y las decisiones de las mujeres sobre sus cuerpos. Consecuentemente, el rol de estas discusiones es hacer al Estado cumplir su obligación de garantizar a los ciudadanos sin discriminación los derechos consagrados en la Declaración Universal de los Derechos Humanos (1945), y en el Pacto Internacional de Derechos Civiles y Políticos (1966), al referir a la libertad de elegir, vivir y llevar la vida deseada. Asimismo, el reconocimiento y la distribución de derechos velan por la convivencia apropiada para generar sociedades más tolerantes, propiciando una democracia que responderá mejor a las demandas de una sociedad diversificada, de manera que no solo se encargue de los aspectos netamente formales, sino que llegue a los aspectos del día a día. Varios teóricos de Latinoamérica, para los cuales los temas sociales cumplen una gran relevancia y junto a quienes se alinean varias teóricas y activistas feministas, mencionan la importancia de tomar en cuenta a la democracia a manera de vivencia diaria, Molyneux desarrolla ampliamente esta discusión en "Género y Ciudadanía en América Latina: cuestiones históricas y contemporáneas" (2000: 21). Por último, es preciso reconocer las implementaciones y varios cambios que permiten un mejor desarrollo de la ciudadanía y una democracia más pluralista, que ha marcado ya el rumbo de un camino de lucha por posicionarse mejor dentro de esa dualidad entre el reconocimiento y la distribución.

\section{Discusiones de Feminismo y género: Grandes expectativas en la esfera pública ecuatoriana}

El Ecuador sigue siendo un país de ideologías conservadoras mucho más 
que progresistas (Balseca, 2017), esto ha ocasionado que no solo el aparataje político se encuentre percutido por la presencia de políticos de antaño y de prácticas políticas de antaño, sino también, es responsable de que la sociedad siga iterando comportamientos, pensamientos y soluciones que responden a esta ideología y que producen estancamientos. Esto ha ocasionado que cualquier lucha "revolucionaria" o "idea renovadora" en la sociedad, sea vista con renuencia, o que se inicie un proceso de promulgación de un progreso de corte "populista", en el que la mayoría de los impulsos progresistas quedan en la retórica de cada nuevo mandatario.

Asimismo, el país tiene grandes retos en cuanto al desarrollo de una democracia de calidad, y más si se considera a la inestabilidad política como el principal obstáculo para su desarrollo procedimental y sustancial, y como la principal productora de corrupción y de desconfianza del pueblo hacia los líderes políticos (IRG, 2007). Así también, la ciudadanía es obstaculizada, pues el goce de derechos y la garantía de los mismos se merman por la ineficiencia de los principales poderes del Estado para ejecutar mecanismos e instaurar ornamentos jurídicos que resuelvan las demandas de las poblaciones; y junto con esto, nuevos tipos de ciudadanías o ciudadanías diferenciadas se leen, permitiendo la creación de estratificaciones en la sociedad. Esto solo perpetúa la lógica de los más favorecidos y los menos favorecidos.

Además, las dos vertientes del ejercicio de la ciudadanía se quedan totalmente invadidas e inmersas en la lógica inequitativa de reconocimiento/ distribución, ya que tanto los aspectos legales de la ciudadanía, como el ejercicio de ésta desde el entendimiento de las particularidades (en cuanto grupo social, étnico, etc.), se desarrollan bajo la tutela de instituciones y representantes que, muchas veces, sesgados por la cosmovisión conservadora, se caracterizan por ser elitistas, heteronormativistas, clasistas, sexistas e inclusive aún racistas (véase por ejemplo el análisis realizado por María Granda 2017, en lo relativo al sexismo y racismo en el discurso sabatino de Rafael Correa, así como la evaluación a los derechos de los pueblos indígenas en Ecuador en Plan V, 2017). Consecuentemente, la brecha de polarización social crece, reflejándose en espacios de acceso a la justicia, a la salud, a la vivienda, al libre pensamiento; en general, al ejercicio de garantías y derechos que como ciudadanos y nacionales del Ecuador se deben gozar. De igual 
forma, el Estado se transforma en quien controla y disciplina a los cuerpos, de manera que no solo distribuye a quienes reconoce, sino que incursiona y destina recursos a quienes cumplen las normativas de tipo demográfico, así como impone el cumplimiento implícito de cierta corporeidad, subjetividad a fin de cuentas legitimándose en una mayoría. Por lo tanto, en términos de Foucault, supondría una lectura del ejercicio del biopoder (Tejeda, 2010: 26).

Tanto para el género como para el feminismo, el proceso de incursión en la discusión de la esfera pública ha sido cuesta arriba. Estos grupos han tenido que lidiar con las concepciones religiosas cristianas y con las morales tradicionales, que se han encargado de transmitir, en términos de Michel Foucault (1970), verdades trascendentales que generan la reproducción de comportamientos aceptados como válidos y legitimados, y otros apuntados como inmorales o descabellados, relegando a la exclusión. Así, aún con pesar, se puede hablar de una sociedad ecuatoriana patriarcal, transversalizada por taxonomías y privilegios que marcan diferenciaciones por edades, raza, educación, estatus, orientación sexual, y que impiden grandes avances en la ciudadanía al reconocer derechos sociales, políticos y civiles (entre estos derechos reproductivos, derechos sexuales, planificación familiar, etc.) y por ende al desarrollo de una democracia pluralista.

No obstante, la lucha de mujeres y de activistas por el género no ha sido en vano y hoy en día existen varias iniciativas públicas, veedurías, instituciones y proyectos de ley a discutir que han llegado a la mirada de la sociedad, ocasionando revueltas y grandes alcances. Así por ejemplo, si se realiza brevemente un análisis retrospectivo del avance en género y feminismo, se pueden notar grandes cambios que datan desde la despenalización de la homosexualidad y especialmente la transexualidad (Registro Oficial \# 736 del 27 de noviembre del 1997) hasta la adjudicación de derechos, civiles como: la Unión de Hecho (Reforma al Código Civil en 2015), la discusión para incluir la identificación sexual en la cédula de identidad (El Comercio, 9 abril 2016) y la participación de personas con identidad diversa a la sexogenérica en la Asamblea Nacional, como es el caso de la elección en el 2017 de Diane Rodríguez: en cuanto al género. Mientras tanto, para la mujer se habló de mayor visibilidad y participación en espacios públicos, hasta la ley de cuotas (desde febrero del 2000, Goyes, s/f: 2) y/o instituciones como el 
Consejo Nacional para la Igualdad de Género, que han puesto un sin número de planes y protocolos para el empoderamiento femenino así como para reducir los casos de femicidio en el país (para octubre 2017, 132 casos [El Universo, 24 noviembre, 2017); y 18 para lo que va del 2018 [El Comercio, 12 marzo 2018]).

A pesar, de la predisposición e iniciativas populares de activistas y de gobiernos, los principales retos para incluir al feminismo y al género en las agendas reales del país recaen de derribar aquellos entendimientos que se han convertido en puntos principales para escritos que algunas teóricas y teóricos han abordado como parte de la "nueva ideología de género" o, mejor dicho, "las ideologías de género de América Latina". En estas discusiones se añade que los feminismos originados en los gobiernos contemporáneos de izquierda, surgen a través de concepciones tradicionales como los roles familiares, la religión y los gobiernos cuasi progresistas, por lo que sus lineamientos se contrapondrían a los fines de las teorías de género que intentan hacer una ruptura en la concepción y formación de estas instituciones, así como, terminar con la normatividad social (Vega, 2017). Así, las teorías género-feministas serán vistas, más bien, como una amenaza al status quo, siendo percibidas y promovidas como problemáticas. Por lo tanto, a la dicotomía del reconocimiento/distribución, se suma comprender, por un lado, los propios fines del feminismo y de las teorías de género versus la realidad conservadora social que estructura un tipo de discurso de género; y, por otro lado, la necesidad del país de adaptar normativas para beneficiar a grupos vulnerados con el fin de velar por la responsabilidad adquirida por instrumentos internacionales versus la acción y ejecución de políticas eficientes.

Así, se puede entender, a partir de dos ejemplos, como oportunidades de generar verdaderos cambios, causar impacto y sentar precedentes para el avance en materia de género y feminismo, sufren un estancamiento y denotan concepciones sociales que todavía son impartidas, compartidas y promovidas en la sociedad, bajo el disfraz del supuesto cambio.

Como primer ejemplo, el reconocimiento de la unión de hecho en el gobierno de Rafael Correa (2007-2017), se torna en una situación 
donde se pone en juego estas dicotomías (reconocimiento/ distribución y fines feministas/ responsabilidad de Estado). En cuanto a la primera, sin lugar a dudas, este hecho constituye el reconocimiento y la ampliación de derechos para la diversidad sexual, pues esta disposición años antes no entraba a discusión en los escenarios públicos; de manera que compone un momento para discutir aspectos que abarcan la ciudadanía, reconociendo particularidades y otorgando en parte para estos grupos la distribución de ornamentos que los respalden.

No obstante, también es un caso, que ameritó la salida a la luz del reconocimiento de un tinte conservador en dicho gobierno y dicho plan político, pues definió y marcó que el matrimonio entre personas del mismo sexo no fue $\mathrm{y}$, muy probablemente no será, tema de discusión para una sociedad que, al parecer, tolera, pero no comparte con todas las causas de estos grupos (véase la entrevista con el expresidente en La Gaceta, 2017). Por lo tanto, si bien se dio paso al reconocimiento parcial de derechos de la comunidad LGBTI, todavía siguen estando en la periferia de la sociedad conservadora, no haciéndose acreedores a la distribución o el goce de otros derechos englobados en la noción de familia y la formalización de la unión conyugal. No está demás aclarar la simbolización y el estatus que representa la sociedad conyugal o matrimonio, no solo respecto a la concepción de la vida familiar como parte de los derechos afiliativos de la persona y, más aun de la dignidad humana, sino en cuanto distribuye un estatus jurídico específico que estipula condiciones, aseguraciones y derechos para manejar el régimen patrimonial de los involucrados (Ventura, 1993: 1-3). Entonces la no permisión de la formalización del matrimonio de parejas del mismo sexo significa que aquellos derechos inherentes a la persona son obstaculizados por el incumplimiento de la norma de heterosexualidad, quedando aquellos individuos fuera de la repartición y reconocimiento. De igual forma, el reconocimiento, en este caso, jugó un doble sentido al visibilizar al grupo excluido (es decir, a la comunidad LGTBI) y a la vez, a preceptos tradicionales de la sociedad.

En cuanto a la segunda dualidad, dentro de los fines del feminismo y de las teorías de género, este hecho es un intento de ahondar y de sentar precedentes sobre la búsqueda de la equidad en la sociedad, así como, de 
adaptar normativas internacionales que proponen el reconocimiento de derechos a estas minorías al tratarse de la dignidad humana y de los derechos que la resguardan. Sin embargo, es claro que no se habló de igualdad en este derecho sino más bien de tolerancia y que se intenta resguardar más que la igualdad de género como se anunciaba, el respeto a la tradición y a la moral reconocida que construyen a la sociedad ecuatoriana de manera normativa; y en donde el matrimonio heterosexual (heteronormativo) es el correcto y el igualitario no es una arista discutible. Consecuentemente, indica los límites aplicables a los fines de estas teorías dentro del país, delimitando a su vez los del reconocimiento y distribución.

Asimismo, como un segundo ejemplo, se comprende por qué en la sociedad resurge la figura maternal de la mujer rencarnada en el proceso de candidatura de Cinthya Viteri (2017), donde de acuerdo a lo referido antes en Molineaux (2000) respecto a la influencia de Eva Perón como la madre de la patria (p. 26), su experticia política es combinada con la promoción de una imagen ligada a la maternidad.

Contrariamente a lo que se creería, la excandidata a la presidencia de la República, intenta mostrarse a la sociedad, más que como una política con una importante trayectoria de militancia dentro de uno de los partidos más tradicionales del país, el Partido Social Cristiano (PSC), o con reiteradas participaciones en la Asamblea Nacional (desde el año 1998) y su profesionalismo como abogada y periodista, con su rol de madre y, por ende, excelente distribuidora de recursos del hogar (o del Estado) y como la madre- mujer que sabrá dirigir la patria. Así ella busca el reconocimiento de la sociedad mediante el velo de lo maternal, y es ella quien se atribuye "ser la madre que salvará al país" (El Comercio, 23 de enero 2017), con la expectativa de acceder al poder y convertirse en quien decida, incluso, cómo llevar a cabo la lógica del reconocimiento/ distribución; lo que implicaría en materia de avances en esta temática tener la posibilidad de generar una ruptura y promoción o una perpetuación.

Por lo tanto, es claro que la candidata no rompe los esquemas y la orden del cumplimiento de la maternidad en algún punto de la vida de la mujer, sino que más bien la figura de lo maternal sirve de atributo 
legitimador para que la sociedad conservadora aún simpatice con la candidatura de ella como madre luchadora más que con la de una mujer. Esto deja entrever que el feminismo actual no dista mucho de aquellos movimientos latinoamericanos de la década de los 60 (véase también Icken, 2009), conservadores y religiosos y que, a pesar de las normativas internacionales adoptadas, el problema sigue estando dentro de los estereotipos tradicionales en la sociedad. Consecuentemente, el objetivo democratizador del país radicaría en cambiar y eliminar aquellas concepciones estereotipadas del género y la asignación de roles para que por fin surja la figura de la mujer líder, profesional, capaz y sensata, y no se revalorice su presencia en lo público únicamente gracias al cumplimiento de una norma que dicta mujer igual a madre. Por lo tanto, de igual forma, dentro de la relación aplicación de marcos internacionales versus fines del feminismo y la sociedad conservadora, se evidencia que la segunda es la predominante dentro de la sociedad ecuatoriana.

Así, se denotan estas principales conclusiones de este apartado. En primer lugar, en el Ecuador, prevalece el feminismo y la construcción de género ligado a la lógica de las relaciones estructuradas de antaño, donde en el imaginario colectivo se entiende que ya hay un (pre)reconocimiento de cuerpos (en términos de Butler, 1992) dentro de la sociedad que concibe un ideal de la imagen tradicional de la mujer, y que ha sido transmitida a lo largo de las épocas de la misma forma. Asimismo, en cuanto a las "normalidades" del género, se entiende que el núcleo de la sociedad (la familia) es la concepción primordial de la sociedad y, por ende, la heteronormatividad (Vega, 2017). Finalmente, a pesar de hablar de nuevos lineamientos, instituciones y discursos sobre lograr la equidad de género, aún sigue siendo un principal desafío, pues presenta como principal obstáculo transformar el imaginario colectivo normado. Así, la equidad de género también es presa de la estructura tradicional de la sociedad, la misma que mantiene un modo de producción de antaño y estratificaciones de clase, de raza, de estatus de antaño. De manera que, al referirse al feminismo, se piensa en aquel que basta con la simple visibilidad de grupos y algún reconocimiento y distribución, en lugar de buscar hacer un punto de inflexión y propiciar el cambio de la estructura. 
En segundo lugar y de la misma manera, se deduce que el problema radica en la transmisión de concepciones que justifica, por ejemplo, que las mismas mujeres sean quienes validen asignaciones que podría mermar el avance de luchas feministas, remarcando roles, heteronormatividades y relaciones patriarcales. Así, dentro del discurso de mujeres hacia lo público todavía prima esa exacerbada valoración a la figura de la madre, relacionada profundamente con el marianismo en cuanto la madre elevada al papel de la Virgen, de la moral suprema y de grandes atributos (Moisés, 2012: 46), siendo parte ellas mismas de la réplica al discurso conservador sobre la mujer. Asimismo, esto denota que la reformulación de estos saberes tomará un periodo de tiempo considerable y que necesita de información y educación de calidad en la materia. Por esta razón, el verdadero avance del género y feminismo, radica no solo en cumplir y comprometerse con la normativa internacional sino en direccionar la normativa nacional y la política interna para crear sociedades renovadas que no solo visibilicen, sino que realicen un cambio, que ejecuten, que mejoren y desarrollen esa democracia del día a día. Solo así, la promoción de entendimientos respecto al género y feminismo evitarán asimetrías e interpretaciones laxas de los fines y luchas que promueven.

\section{Consideraciones finales}

Este escrito buscó incursionar y referenciar las nuevas discusiones alrededor de las definiciones del género y del feminismo con el fin de entenderlas en el mundo contemporáneo y transversalizarlas con varios aspectos que forman parte ahora de su definición ampliada. Así, para logar este cometido, a lo largo de este ensayo, se efectuó una revisión de manera histórica-descriptiva y breve de las diferentes caracterizaciones o nuevas taxonomías que actualmente son puntos de inflexión, entendiéndolas a través de la comprensión de la dualidad propuesta por Fraser (2015), del reconocimiento/ distribución. Esta dualidad o lógica tal como se revisó, se concibe en una sociedad estructurada de forma dispar, en la cual el reconocimiento y la distribución no ocurre de manera equitativa y, por lo tanto, se caracteriza por reconocer y distribuir más a unos que a otros, afectando el desarrollo de la misma. En esta lógica se incluyen 
aspectos como los denominados privilegios de género y las acciones de los principales actores estatales.

Asimismo, este escrito rastrea esta dualidad en tres diferentes apartados que, a su vez, abarcan discusiones que el feminismo y el género elevan a la esfera pública, acunándolas para ser parte de sus fines y luchas. El primer apartado realiza una revisión teórica del feminismo, su ampliación ligada a los acontecimientos históricos y la adhesión de nociones como el género como sujeto inmerso en la lucha, los privilegios como importantes consideraciones y las variedades de feminismo que presentan partículas distintivas en sus causas. De igual forma, se discute la importancia de entender y trazar lineamientos en las teorías y en la promoción de fines del movimiento para combatir el aparecimiento de contra-teorías, anti-conceptos y malos entendimientos (como el hembrismo y la aparición de nociones como femi-nazi) que merman el avance de las teorías de género. Como resultado, el énfasis de este apartado radica en anexar y relacionar a la definición estándar del feminismo, aportes y discusiones que forman parte de su entender; así como, indicar los posibles riesgos de la ampliación conceptual.

El segundo apartado por su parte, discutió la importante inserción y consideración del género y feminismo para el desarrollo de las nociones de democracia y de ciudadanía. Consecuentemente, para el cumplimiento de este objetivo, se realizó una breve alusión histórica de la evolución de las teorías de estos movimientos, destacando como importantes, el cambio de concepción de la subjetividad de la mujer, la adquisición de derechos de la diversidad sexual y de mujeres, y la visibilidad en el espacio público. De igual forma, se comprende en este apartado cómo actúa la lógica del reconocimiento-distribución, resaltando aspectos que determinan y denotan el accionar de los principales poderes del Estado para el alcance de la paridad, planteando también dilemas que surgen alrededor de las efectividades de las ramas estatales. Así, de este apartado se concluye que el reconocimiento del género y de las propuestas del feminismo, es un factor crucial para el desarrollo de la democracia y la ciudadanía, por lo que, si bien existen ya avances logrados a lo largo de las épocas, aún hay mucha trayectoria por recorrer y trabajo por hacer. 
Finalmente, en el último apartado convergieron las discusiones propuestas anteriormente la transversalidad del género, los privilegios, los hechos o hitos históricos, y se discutió y visibilizó de manera corta los avances en estos movimientos en el Ecuador dentro del entendimiento de la relevancia de éstos para el desarrollo de la democracia y de la ciudadanía. Así, mediante dos ejemplos, se puso en juego la dualidad del reconocimientodistribución, que permitieron develar y comprender que el país aún presenta varios retos por alcanzar en cuanto al verdadero alcance de la equidad de género como pilar fundamental de la dignidad humana y como directriz parte de varios instrumentos internacionales en materia de derechos humanos (véase la Declaración Universal de los Derechos Humanos de 1945).

Asimismo, dentro de las principales implicaciones para la falta del desarrollo de una democracia igualitaria y plural y para la eliminación de ciudadanías de segunda clase, figuran, por un lado, obstáculos no solo del tipo de alto grado de corrupción y la falta de confianza en el régimen, sino de acción y de promoción de progreso y de equidad no solo de forma retórica, sino práctica. Mientras que, por otro lado, figura la persistencia de concepciones tradicionalistas enraizadas en el imaginario social; tales como la heteronormatividad ligada a la familia convencional (Vega 2017) y la imagen tradicional de la mujer y su rol de madre (estereotipos), que caracterizan a la sociedad de conservadora. Esto indica que la educación en materia de derechos humanos, género y mujer tiene que ser reforzada, revaluada y comprendida, de manera que no repliquen conductas que frenen avances, que generen estereotipos o que terminen invalidadas por mal entendimiento. Finalmente, si se propone alcanzar la definición más adecuada de feminismo, se reconocería que tal concepción solo podría darse bajo el entendimiento de que este término agrupa un sinnúmero de particularidades que representan realidades como: tipo poblacional, privilegios de raza, clase, etnia o identidades y preferencias sexuales. Sin embargo, es preciso que se entienda que, sobre cualquiera de estas particularidades, el desarrollo de la equidad entre hombres y mujeres o de género debe suceder enmarcado en la lógica de igual reconocimiento e igual distribución. 


\section{Referencias}

Amigot, Patricia. \& Pujal, Margot. (2009). Una lectura del género como dispositivo de poder. En Sociológica, año 24, número 70, mayo-agosto de 2009, pp. 115-152.Recuperado de http://www.scielo.org.mx/pdf/soc/ v24n70/v24n70a5.pdfArboleda, Carmen. (2017). La quinta avenida de nueva york se llenó de manifestantes y público celebrando el día del orgullo gay. En Ecuador News, 28 de junio. Recuperado de: http://www. ecuadornews.com.ec/dia-del-orgullo-gay/

Balseca, Fernando. (2017). "Progresistas irrealistas". En El Universo, 29 de septiembre. Recuperado de: https:/www.eluniverso.com/ opinion/2017/09/29/nota/6405562/progresistas-irrealistas

Butler, Judith. (1990). El género en disputa. Feminismo y la subversión de la identidad. Barcelona España: Paidós.

Butler, Judith. (1992). Fundamentos contingentes. Feminismo y la cuestión del posmodernismo.

Butler, Judith. (2002). Cuerpos que Importan. Sobre los limites materiales y discursivos del "sexo". Buenos Aires- Argentina: Paidós.

Cimanoticias. (septiembre 2016). "Bancada Feminista trabajará por una Constitución que profundice la equidad. Noticias con perspectiva de género". Recuperado de: http://www.cimacnoticias.com.mx/noticia/ bancada-feminista-trabajar-por-una-constituci-n-que-profundice-laequidad

Devitt, Amy J. (2004). Writing Genres. Southern Ilinoise University Press.

Declaración Universal de los Derechos Humanos. (1945). Artículo. 1

Dahl, Robert. (1989). La poliarquía: participación y oposición. Editorial Tecnos. 
El Comercio. (23 enero 2017). "Cynthia Viteri se ve como la madre que salvará al país". Recuperado de: http://www.elcomercio.com/actualidad/ cynthiaviteri-madre-salvacion-ecuador-elecciones2017.html

El Comercio. (12 marzo, 2018). "Ecuador registra 18 femicidios en lo que va del 2018, según varias ONG”. Recuperado de: http://www.elcomercio. com/actualidad/ecuador-femicidios-violencia-mujer-seguridad.html

El Comercio. (9 abril 2016). "La unión de hecho es el mayor avance de los GLBTI en Ecuador”. Recuperado de: http://www.elcomercio.com/ actualidad/union-hecho-avance-glbti-ecuador.html

El Universo. (24 noviembre, 2017). "Los Casos de Femicidio en el 2017”. Recuperado de: https://www.eluniverso.com/noticias/2017/11/24/ nota/6493684/casos-femicidio-2017-ecuador

Granda, María. (2017). El macho sabio. Racismo y sexismo en el discurso sabatino de Rafael Correa. En Ecuador Debate. Quito - Ecuador

Goyes, Solanda. (s/f). Cumplimiento parcial de la Ley de Cuotas. Cepal. Recuperado de:https:/oig.cepal.org/sites/default/files/2002_res0282002-tc_ecu.pdf

Facio, Alda. y Fries, Lorena. (1999). "Feminismo, género y patriarcado. La Morada". Chile. Recuperado de: http://www.observatoriojusticiaygenero. gob.do/documentos/PDF/publicaciones/Lib_genero_derecho.pdf

Fraser, Nancy. (2015). Fortunas del Feminismo del Capitalismo Gestionado por el Estado a la Crisis Neoliberal. IAEN.

Foucault, Mitchel. (1970). El orden del Discurso. Editorial Fábula Tus Quests.

Heras, Samara. (2009). Una aproximación a las teorías feministas. 
Universitas. Revista de Filosofía, Derecho y Política.

Icken, Helen. (2009). "Women's Social Movement in Latin America. En Genre and Society". Vol. 4, No.3 Special Issue: Women and Development in the Third World. (Sep. 1990). Pp. 354-369.

Instituto Nacional contra la Discriminación, la Xenofobia y el Racismo INADI. (2016). "Diversidad sexual y derechos humanos: sexualidades libres de violencia y discriminación". Dirigido por Javier Alejandro Bujan. - 1a ed. - Ciudad Autónoma de Buenos Aires: Instituto Nacional contra la Discriminación, la Xenofobia y el Racismo.

IRG. Instituto de investigación y debate sobre la gobernanza. (2007). Presentación de algunos factores de inestabilidad política en el Ecuador. Recuperado de: http://www.institut-gouvernance.org/bdf/es/conference/ fiche-conference-27.html

Kymlicka, Will. \& Norman, Wayne. (1994). El retorno del ciudadano. Una revisión de la producción reciente en teoría de la ciudadanía. Publicación original en The University of Chicago Press, enero de 1994, págs. 257-289. Versión en castellano en Cuadernos del CLAEH, n0 75, Montevideo, 1996, págs. 81-112. AgorA núm. 7/invierno de 1997, pags. $5-42$.

Molyneux, Maxine. (2000). Women's Movements in international Perspective: Latin America and Beyond. Palgrave, Nueva York, Londres.Cap.7

Moisés, Alfonso. (2012). "Sexualidad en Mesoamérica: machismo y marianismo". en Científica, Vol. 1, № 1, época 2, pp. 45-53

Mouffe, Chantal. (1999). El Retorno de lo Político, comunidad, ciudadanía, pluralismo, democracia radical. Verso.

Plan V. (2017). "Las caras racistas de Ecuador". 06 de agosto. Recuperado 
de: http://www.planv.com.ec/historias/sociedad/caras-racistas-ecuador

Quiroga, Hugo. (2000). “¿Democracia procedimental o democracia sustantiva? La opción por un modelo de integración”. En Revista de Ciencias Sociales (Ve), vol. VI, núm. 3, septiembre-diciembre, 2000, pp. 361-374.

Segato, Rita. (2007). La Nación y sus Otros: raza, etnicidad y diversidad religiosa en tiempos de Políticas de la Identidad. Buenos Aires, Prometeo Libros.

Tejeda, José. (2010). Biopolitica, población y control. BIBHUMA.

Troya, María del Pilar. (2001). No soy Machista, pero... en Masculinidades en Ecuador. Flacso Ecuador. Recuperado de: http://www.flacso.org.ec/ docs/samastroya.pdf

Vega, Sofía. (2014). Sumak Kawsay, Feminismos y Post-crecimientos: Articulaciones para imaginar nuevas utopías. En: Post-Crecimiento y Buen Vivir. Propuestas globales para construcción de sociedades equitativas y sustentables. Ed. Friedrich Ebert Stiftung.

Vega, Cristina. (2017/). “QQuién teme al feminismo? A propósito de la "ideología de género" y otras monstruosidades sexuales en Ecuador y América Latina". En Sin Permiso. Recuperado de: http:/www. sinpermiso.info/textos/quien-teme-al-feminismo-a-proposito-de-laideologia-de-genero-y-otras-monstruosidades-sexuales-en 